\title{
Hastes florais de helicônia sob deficiência de macronutrientes
}

\author{
Ana Cecília Ribeiro de Castro(1), Vivian Loges ${ }^{(2)}$, Andreza Santos da Costa ${ }^{(2)}$, Mario Felipe Arruda de Castro(2), \\ Fernando Antônio Souza de Aragão ${ }^{(1)}$ e Lilia Gomes Willadino (2)
}

\begin{abstract}
(1)Embrapa Agroindústria Tropical, Caixa Postal 3761, CEP 60511-110 Fortaleza, CE. E mail: cecilia@cnpat.embrapa.br, aragao@cnpat.embrapa.br (2)Universidade Federal Rural de Pernambuco, Av. Dom Manuel de Medeiros, s/no, CEP 52171-900 Recife, PE. E mail: vloges@yahoo.com, andreza.costa@gmail.com, mariocastro@alldeia.com.br, lilia@pq.cnpq.br
\end{abstract}

\begin{abstract}
Resumo - O objetivo deste trabalho foi avaliar características pós-colheita da primeira haste floral de plantas de Heliconia psittacorum x H. spathocircinata Aristeguieta, cultivar Golden Torch, sob deficiência de macronutrientes. O experimento foi conduzido em casa de vegetação, mediante técnica do elemento faltante. As inflorescências produzidas do tratamento sob omissão de $\mathrm{N}$ apresentaram coloração laranja-pálido e deformação nas hastes florais. O comprimento e o diâmetro da haste floral e o comprimento da inflorescência foram reduzidos nos tratamentos com omissão de N, P ou K em até 31,23\%, em relação ao tratamento completo. A massa de matéria seca e a durabilidade pós-colheita das hastes florais foram reduzidas em 67 e 38,46\%, respectivamente, em ambos os tratamentos com omissão de $\mathrm{N}$ ou K . As deficiências desses macronutrientes reduziram, ainda, a produção de hastes florais, a partir do segundo perfilho emitido. Hastes florais com maior massa de matéria seca e diâmetro apresentaram maior durabilidade pós-colheita. $\mathrm{O}$ teor de carboidrato na parte subterrânea mostrou correlação positiva $(0,90)$ com a massa de matéria seca das hastes florais. Hastes florais com maior teor de carboidratos solúveis nas folhas retardaram a emissão da inflorescência.
\end{abstract}

Termos para indexação: qualidade da inflorescência, flor de corte, flores tropicais, duração de vida pós-colheita.

\section{Flower stems postharvest characteristics of heliconia under macronutrients deficiency}

\begin{abstract}
The objective of this work was to evaluate Heliconia psittacorum x H. spathocircinata Aristeguieta 'Golden Torch' first flower stem morphological and physiological characteristics as well as postharvest longevity, under macronutrients omissions. A greenhouse experiment was conducted under the technique of the lacking element. Inflorescences produced under $\mathrm{N}$ omission treatment showed a pale orange color and floral stem deformation. Stem length and diameter as well as inflorescence length were reduced under omission of N, P or K, down to $31.23 \%$ when compared to the complete solution treatment. Floral stem dry matter and postharvest longevity were reduced on $67 \%$ and $38.46 \%$, respectively, on either $\mathrm{N}$ or K omission treatments. These nutrients omission treatments reduced floral stem production from the second shoot emitted. Greater postharvest longevity is to be found at higher floral stem diameter and dry matter. Carbohydrate ratio in underground parts presents positive correlation (0.90) with floral stem dry matter. Floral stems showing greater carbohydrate ratio on the leaves withdraw inflorescence appearance.
\end{abstract}

Index terms: inflorescence quality, cut flowers, tropical flowers, postharvest life duration.

\section{Introdução}

O mercado mundial de flores tropicais apresenta elevado potencial de crescimento uma vez que os consumidores de países de clima temperado valorizam este produto. As exportações brasileiras de flores e plantas cresceram mais de $124 \%$ entre 2001 e 2006 , mantendo crescimento real de pelo menos $10 \%$ ao ano (Junqueira \& Peetz, 2007).
No Brasil, o cultivo de flores tropicais é realizado, principalmente, nos estados de Pernambuco, Alagoas, Ceará, Bahia, Sergipe, Pará, Amazonas, Rio de Janeiro e São Paulo e no Distrito Federal (Junqueira \& Peetz, 2005). Pernambuco, Alagoas e Ceará foram os principais estados exportadores desse tipo de flores (Junqueira \& Peetz, 2007).

As helicônias se destacam pela beleza e variedade de formas e cores e estão entre as flores tropicais com 
maior aceitação nos Estados Unidos e países da Europa, tais como Holanda, Portugal, Espanha, França, Alemanha e Itália (Vallespir, 2005).

A Heliconia psittacorum x $H$. spathocircinata Aristeguieta cultivar Golden Torch é uma das helicônias mais comercializadas no mundo. Destaca-se por ser muito produtiva e florescer o ano inteiro (Costa, 2005). Sua inflorescência terminal é ereta e possui de quatro a oito brácteas de cor amarelo-alaranjada com flores alaranjadas em seu interior. Em relação à adequação como flor de corte, apresenta inflorescência leve, com brácteas dispostas em um mesmo plano o que facilita o acondicionamento em caixas (Loges et al., 2005).

A durabilidade pós-colheita é um dos principais aspectos a serem observados na produção de flores para corte. Além disso, constitui um pré-requisito para a qualidade do produto e para o sucesso da comercialização. Entre os fatores que influenciam esses aspectos está o manejo pré-colheita que envolve propriedades nutricionais da cultura. A adubação inadequada pode acarretar deficiências nutricionais e afetar o desenvolvimento, a produtividade e a qualidade do produto comercial, conseqüência da redução do acúmulo de fotoassimilados, principalmente carboidratos. As flores de corte com maior concentração de carboidratos apresentam maior durabilidade pós-colheita (Nowak \& Rudnicki, 1990; Marissen, 2001).

Existe variação na recomendação de adubação para helicônias (Clemens \& Morton, 1999; Lamas, 2002). Essas recomendações não consideram as diferentes fases de desenvolvimento da cultura e exigência nutricional de espécies e cultivares de helicônias, uma vez que estas respondem diferentemente à aplicação da adubação de NPK (Ferreira \& Oliveira, 2003).

O objetivo deste trabalho foi avaliar características pós-colheita da primeira haste floral de plantas de Heliconia psittacorum $\mathrm{x} H$. spathocircinata cultivar Golden Torch, sob deficiência de macronutrientes.

\section{Material e Métodos}

O experimento foi conduzido em casa de vegetação do Dep. de Agronomia da Universidade Federal Rural de Pernambuco, Recife, PE, de setembro de 2004 a maio de 2005. Foram utilizados rizomas de Heliconia psittacorum x $H$. spathocircinata Aristeguieta cultivar Golden Torch, selecionados com $30 \mathrm{~cm}$ de comprimento e $120 \mathrm{~g}$ de matéria fresca. Na limpeza dos rizomas, as raízes foram removidas. Em seguida, os rizomas foram lavados com água desmineralizada e secados ao ar.
O delineamento experimental foi inteiramente casualizado com dez repetições por tratamento, sendo a unidade experimental, um rizoma por vaso. Os rizomas foram plantados em vasos de plástico preto, com capacidade de $12 \mathrm{~L}$, contendo substrato composto exclusivamente de areia grossa lavada e peneirada (com malha de $2 \mathrm{~mm}$ ), coberta por uma camada de $3 \mathrm{~cm}$ de brita, a fim de reduzir a evaporação da superfície do substrato.

As plantas foram irrigadas diariamente apenas com água destilada durante os 30 dias iniciais. Após este período, foram realizados tratamentos completos que consistiram de solução de Hoagland a $1 \frac{1}{2}$ força iônica (Hoagland \& Arnon, 1951) e ausência de macronutrientes (água), e os demais tratamentos constituídos por solução nutritiva, a $1 / 2$ força iônica, com a omissão de N, P, K, Ca, Mg ou S, o que totalizou oito tratamentos.

Na prevenção do acúmulo de sais ou depleções de nutrientes, os tratamentos foram irrigados diariamente com o volume de solução equivalente à sua capacidade de pote acrescido de $25 \%$, e a cada sete dias irrigados com água em duas vezes a capacidade de pote. $\mathrm{O}$ pH das soluções foi mantido em torno de 5,5, pelo uso de $\mathrm{NaOH}$ ou $\mathrm{HCl}$.

Os perfilhos emitidos foram identificados e, na observação da produção de hastes florais, foram utilizadas cinco repetições escolhidas aleatoriamente. Após o início do florescimento, as primeiras hastes florais de cada tratamento foram colhidas quando as inflorescências apresentavam duas brácteas abertas. As avaliações foram realizadas até 260 dias após o plantio (DAP).

As hastes foram cortadas, pela manhã, no nível do substrato de cultivo e os seguintes caracteres foram avaliados: número de dias para emissão do perfilho (NDEP); número de dias para emissão da inflorescência, a partir da formação do perfilho (NDEI); número de dias para a colheita da inflorescência a partir da sua emissão (NDCI); número de dias a partir da emissão do perfilho até a data da colheita (CICLO); massa de matéria seca da haste floral sem as folhas (MSH), determinada após a avaliação da durabilidade pós-colheita; diâmetro da haste medido a $20 \mathrm{~cm}$ abaixo da inflorescência (DH); comprimento da haste floral, medido da base do pseudocaule ao ápice da inflorescência $(\mathrm{CH})$; comprimento da inflorescência, medido da parte colorida do pedúnculo ao ápice da inflorescência (CI) e durabilidade pós-colheita em dias 
(POSC). Os teores de carboidratos solúveis totais da parte subterrânea (raízes + rizoma) (CBS), das folhas (CBF) e das hastes florais ( $\mathrm{CBH}$ ), foram determinados pelo Método de Antrona (Bezerra Neto \& Barreto, 2004), após a avaliação da POSC.

Para a obtenção da POSC, imediatamente após as medições dos caracteres, as hastes florais foram colocadas em recipientes com água deionizada, renovada a cada dois dias. As hastes foram mantidas em sala refrigerada a $25^{\circ} \mathrm{C}$, em níveis de luminosidade de $15 \mu \mathrm{mol} \mathrm{m}{ }^{-2} \mathrm{~s}^{-1}$. A fonte de luz foi parcialmente fornecida por tubos de lâmpada fluorescente fria (General Electric F400 Extralife, 40W) e luz proveniente do ambiente exterior. A umidade relativa média da sala foi de aproximadamente $75 \%$. As avaliações foram diárias e realizadas sob o critério de notas adaptado de Castro (1993): nota 0, aspecto geral excelente (aspecto de recém-colhido); nota 1 , aspecto geral bom (sinais de senescência pouco característicos, com perda de brilho); nota 2, aspecto geral regular (com início de murcha ou com discreto escurecimento das brácteas).

A POSC foi obtida a partir da média do número de dias até a obtenção da nota 2.

Os dados foram submetidos à análise de variância e as médias comparadas pelo teste de Tukey, a 5\% de probabilidade. A análise de coeficiente de correlação simples das médias (teste $t$ de Student) foi realizada com base nas médias de cada tratamento nas 13 características avaliadas pelo coeficiente de correlação de Pearson (r).

\section{Resultados e Discussão}

A omissão de macronutrientes em Heliconia psittacorum x H. spathocircinata cultivar Golden Torch influenciou, significativamente, o número de dias para emissão da inflorescência (NDEI); o número de dias para a colheita da inflorescência a partir da sua emissão (NDCI); o número de dias a partir da emissão do perfilho até a data da colheita (CICLO); a massa de matéria seca da haste floral sem as folhas (MSH); o diâmetro da haste (DH); o comprimento da haste floral (CH); o comprimento da inflorescência (CI) e a durabilidade pós-colheita (POSC), à exceção de número de dias para emissão do primeiro perfilho (NDEP) (Tabela 1).

O NDEP foi 21,20 dias, em média, para os tratamentos. Nesta fase inicial de desenvolvimento, as plantas ainda não haviam sido submetidas aos tratamentos, portanto, este crescimento inicial deve-se exclusivamente às reservas dos rizomas.

As plantas do tratamento completo apresentaram número de dias para emissão de inflorescência (NDEI) de 165,20, e diferiram dos demais tratamentos, à exceção do tratamento com omissão de $\mathrm{Mg}$ (165,80 dias). Em experimentos com adubação completa foram registrados, para essa cultivar, os seguintes resultados: 168 dias em vaso (Catley \& Brooking, 1996a); 99,28 dias a pleno sol e 111,09 dias sob sombreamento em campo (Costa, 2005); 150 dias, em condições de campo (Ferreira \& Oliveira, 2003). Essas variações são, provavelmente, influenciadas pelas condições em que as plantas foram expostas. A omissão de P foi o tratamento que resultou em maior NDEI, de 195,60 dias.

Tabela 1. Características de ciclo e produção da primeira haste floral de helicônia da cultivar Golden Torch (Heliconia psittacorum x H. spathocircinata), cultivada em diferentes soluções de nutrientes ${ }^{(1)}$.

\begin{tabular}{|c|c|c|c|c|c|c|c|c|}
\hline Tratamento & NDEP & NDEI & NDCI & CICLO & MSH & $\mathrm{DH}$ & $\mathrm{CH}$ & $\mathrm{CI}$ \\
\hline Completo & $21,0 \mathrm{a}$ & $165,2 \mathrm{e}$ & $19,4 a$ & $184,6 \mathrm{c}$ & $4,91 \mathrm{a}$ & $6,66 \mathrm{a}$ & $84,6 b c$ & $18,6 \mathrm{a}$ \\
\hline Omissão de $\mathrm{N}$ & $21,0 \mathrm{a}$ & $172,0 \mathrm{c}$ & $16,8 \mathrm{~b}$ & $188,8 b$ & $1,62 \mathrm{e}$ & $4,58 b$ & $76,4 \mathrm{c}$ & $13,2 \mathrm{c}$ \\
\hline Omissão de P & $23,8 \mathrm{a}$ & $195,6 \mathrm{a}$ & $15,2 b c$ & $210,8 \mathrm{a}$ & $3,55 \mathrm{bc}$ & $5,36 b$ & $80,5 b c$ & $15,0 \mathrm{bc}$ \\
\hline Omissão de $\mathrm{K}$ & $21,0 \mathrm{a}$ & $176,8 b$ & $14,0 \mathrm{c}$ & $190,8 b$ & $2,41 d$ & $4,64 b$ & $66,4 d$ & $14,7 \mathrm{c}$ \\
\hline Omissão de Ca & $19,6 \mathrm{a}$ & $172,0 \mathrm{c}$ & $11,6 \mathrm{~d}$ & $184,0 \mathrm{c}$ & $3,18 \mathrm{c}$ & $6,91 \mathrm{a}$ & $95,3 a$ & $18,4 \mathrm{a}$ \\
\hline Omissão de $\mathrm{Mg}$ & $21,0 \mathrm{a}$ & $165,8 \mathrm{e}$ & $15,4 \mathrm{bc}$ & $181,2 d$ & $3,00 \mathrm{~cd}$ & $6,67 \mathrm{a}$ & $88,1 \mathrm{ab}$ & $19,8 \mathrm{a}$ \\
\hline Omissão de $\mathrm{S}$ & $21,0 \mathrm{a}$ & $169,2 d$ & $18,8 \mathrm{~b}$ & $182,0 \mathrm{c}$ & $3,98 \mathrm{~b}$ & $6,80 \mathrm{a}$ & $82,8 \mathrm{bc}$ & $17,5 \mathrm{ab}$ \\
\hline Média & 21,20 & 173,80 & 15,88 & 188,89 & 3,24 & 5,94 & 82,01 & 16,74 \\
\hline CV $(\%)$ & 24,33 & 9,56 & 34,56 & 33,81 & 11,29 & 9,58 & 5,88 & 7,36 \\
\hline
\end{tabular}

${ }^{(1)}$ Médias seguidas da mesma letra na coluna não diferem entre si pelo teste de Tukey, a 5\% de probabilidade; NDEP, número de dias para emissão de perfilhos; NDEI, número de dias para emissão da inflorescência a partir da formação do perfilho; NDCI, número de dias para a colheita da inflorescência a partir da sua emissão; CICLO, número de dias a partir da emissão do perfilho até a data da colheita; MSH (g), massa da matéria seca da haste floral, sem as folhas, determinada após a avaliação da durabilidade pós-colheita; DH (mm), diâmetro da haste 20 cm abaixo da inflorescência; $\mathrm{CH}(\mathrm{cm})$, comprimento da haste, medido da base do pseudocaule ao ápice da inflorescência; CI (cm), comprimento da inflorescência, medido da parte colorida do pedúnculo ao ápice da inflorescência. 
Plantas sob deficiência de $\mathrm{P}$ apresentam atraso no florescimento (Malavolta, 2006), e alteração na formação de botões florais, de frutos e de sementes (Mengel \& Kirkby, 2001). Em diversas culturas, o efeito do P na floração sugere que esse macronutriente está relacionado com mudanças nos níveis de fitormônios envolvidos nessa fenofase (Marschner, 1995).

O maior número de dias para colheita da inflorescência a partir da sua emissão (NDCI) foi observado no tratamento completo (19,40 dias), que diferiu de todos os outros tratamentos. Este valor foi semelhante aos observados em cultivo de campo, com a mesma cultivar, por Costa (2005). A omissão de Ca acarretou o menor NDCI (11,60 dias).

O ciclo das plantas do tratamento completo foi de 184,60 dias, não diferindo dos tratamentos com omissão de Ca (184,00 dias) e S (186,00 dias). O menor ciclo foi observado nas plantas com omissão de $\mathrm{Mg}$ (181,20 dias). A omissão de P acarretou o maior ciclo (210,80 dias), o que confirma a influência desse nutriente na floração (Malavolta, 2006). Catley \& Brooking (1986a) observaram ciclo de 180 dias em plantas de helicônia cultivar Golden Torch, em vaso com nutrição completa. Salomão et al. (2006) verificaram uma crescente exigência de $\mathrm{P}$ no período de florescimento em plantas de lichia (Litchi chinensis).

A massa de matéria seca da haste floral sem as folhas (MSH) do tratamento completo (4,91 g) diferiu dos demais tratamentos. O nutriente que mais influenciou a produção da MSH foi o N (1,62 g), o que acarretou redução de 67\% em comparação com as plantas cultivadas com solução completa. A redução da massa de matéria seca em razão da carência de $\mathrm{N}$ é relatada em diversas culturas ornamentais, como Spathiphyllum (Yeh et al., 2000) e Helianthus annus (Cechin \& Fumis, 2004).

O diâmetro da haste (DH) foi de 6,66 mm nas plantas do tratamento completo, e não diferiu dos tratamentos com omissão de $\mathrm{Ca}, \mathrm{Mg}$ e $\mathrm{S}$, e superior às plantas dos tratamentos com omissão de $\mathrm{N}(4,58 \mathrm{~mm}), \mathrm{P}(5,36 \mathrm{~mm})$ e K (4,64 mm). Em Heliconia cultivar Golden Torch e Heliconia cultivar Vincent Red a omissão de N, P e K, em condições de campo, também reduziu o diâmetro da haste floral (Ferreira \& Oliveira, 2003). Hastes com diâmetros maiores são mais rígidas, o que reduz o tombamento e quebra na colheita e pós-colheita (Nowak \& Rudnicki, 1990).

O comprimento da haste $(\mathrm{CH})$ do tratamento completo foi de $84,60 \mathrm{~cm}$ e não diferiu das hastes das plantas dos tratamentos com omissão de $\mathrm{Mg}, \mathrm{S}, \mathrm{P}$ e N. As plantas do tratamento com omissão de Ca produziram flores com maior $\mathrm{CH}(95,30 \mathrm{~cm})$, comparativamente ao tratamento completo. $\mathrm{O}$ menor $\mathrm{CH}$ foi observado no tratamento com omissão de $\mathrm{K}(66,40 \mathrm{~cm})$, fato também detectado por Fernandes (2000), em condições de campo em $H$. psittacorum conduzidas com deficiência de K. O coeficiente de correlação (r) de 0,85 , significativo a $5 \%$, entre $\mathrm{CH}$ e $\mathrm{DH}$ é indicação de que hastes florais com maiores comprimentos apresentam diâmetros maiores.

Em relação ao comprimento de inflorescência CI, as plantas do tratamento completo tiveram inflorescências com 18,60 cm e não diferiram dos tratamentos com omissão de $\mathrm{Mg}$ e Ca, os quais apresentaram os maiores valores. Os menores valores foram observados nas plantas com omissão de $\mathrm{N}(13,20 \mathrm{~cm})$ e $\mathrm{K}(14,70 \mathrm{~cm})$. $\mathrm{O} C \mathrm{C}$ apresentou correlação positiva $\operatorname{com} \mathrm{CH}(\mathrm{r}=0,75)$ e DH $(r=0,93)$, isto é, hastes florais com maior comprimento e diâmetro apresentaram inflorescências maiores. Este fato foi perceptível nos tratamentos em que a omissão dos macronutrientes prejudicou essas características qualitativas da haste.

Foi observado escurecimento gradual das brácteas durante o processo de senescência das inflorescências na pós-colheita. O tratamento completo apresentou maior durabilidade pós-colheita (POSC), que foi de 15,60 dias (Tabela 2), diferindo dos demais tratamentos. Broschat (1985) e Donselman \& Broschat (1986) observaram durabilidades póscolheita de $H$. psittacorum de 12 a 24 dias. A omissão de $\mathrm{K}$ acarretou a menor POSC (9,60 dias). A omissão

Tabela 2. Durabilidade pós-colheita e teor de carboidrato da primeira haste floral de helicônia, cultivar Golden Torch (Heliconia psittacorum x H. spathocircinata), cultivada sob diferentes soluções de nutrientes ${ }^{(1)}$.

\begin{tabular}{lclcc}
\hline Tratamento & POSC & CBF & CBS & CBH \\
\hline Completo & $15,60 \mathrm{a}$ & $14,04 \mathrm{~d}$ & $32,30 \mathrm{a}$ & $27,06 \mathrm{a}$ \\
Omissão de N & $10,80 \mathrm{~cd}$ & $24,52 \mathrm{bc}$ & $4,67 \mathrm{~d}$ & $5,27 \mathrm{c}$ \\
Omissão de P & $11,20 \mathrm{~cd}$ & $35,25 \mathrm{a}$ & $19,39 \mathrm{bc}$ & $3,92 \mathrm{c}$ \\
Omissão de K & $9,60 \mathrm{~d}$ & $30,33 \mathrm{ab}$ & $12,90 \mathrm{~cd}$ & $20,65 \mathrm{ab}$ \\
Omissão de Ca & $12,80 \mathrm{bc}$ & $13,67 \mathrm{~d}$ & $7,86 \mathrm{~d}$ & $17,10 \mathrm{~b}$ \\
Omissão de Mg & $11,60 \mathrm{bcd}$ & $20,11 \mathrm{~cd}$ & $19,96 \mathrm{bc}$ & $17,57 \mathrm{~b}$ \\
Omissão de S & $14,00 \mathrm{ab}$ & $24,32 \mathrm{bc}$ & $25,21 \mathrm{ab}$ & $19,17 \mathrm{ab}$ \\
\hline Média & 12,22 & 23,18 & 17,47 & 15,82 \\
CV (\%) & 8,76 & 21,47 & 23,71 & 29,11 \\
\hline
\end{tabular}

(1)Médias seguidas da mesma letra na coluna não diferem entre si pelo teste de Tukey, a 5\% de probabilidade; POSC, durabilidade pós-colheita em dias; $\mathrm{CBF}\left(\mathrm{mg} \mathrm{L}^{-1}\right)$, teor de carboidrato solúvel total das folhas; CBS (mg L $\left.{ }^{-1}\right)$, teor de carboidrato solúvel total da parte subterrânea (raízes + rizoma); $\mathrm{CBH}\left(\mathrm{mg} \mathrm{L}^{-1}\right)$, teor de carboidrato solúvel total das hastes florais. 
de $\mathrm{N}$ acarretou POSC de 10,80 dias, inferior aos resultados observados no tratamento completo. Druege $(2000,2001)$ destaca que teores adequados de $\mathrm{N}$ na nutrição de uma planta ornamental favorecem a durabilidade pós-colheita.

A durabilidade pós-colheita (POSC) apresentou correlações positivas com MSH $(\mathrm{r}=0,86)$ e $\mathrm{DH}$ $(\mathrm{r}=0,78)$, o que demonstra que hastes florais que apresentam maior produção de matéria seca e maiores diâmetros apresentam maior durabilidade, que variou de 9 a 15 dias, de acordo com os resultados apresentados. A redução de até $38,46 \%$ na POSC, $67 \%$ na MSH e $31,23 \%$ no DH nos tratamentos com omissão de N, P e $\mathrm{K}$, em comparação com o tratamento completo, confirma essas correlações. Em geral, nas flores de corte, a reserva de carbono contida na haste é utilizada para estender a longevidade potencial das flores e, quanto maior o comprimento e o diâmetro da haste, maior a durabilidade pós-colheita (Kays, 1991). As flores de corte, ao serem separadas da planta, não recebem mais nutrientes e dependem inteiramente de suas reservas (Druege, 2001).

Os teores de carboidratos foram maiores na parte subterrânea (CBS) e nas hastes florais $(\mathrm{CBH})$ e menores nas folhas (CBF) no tratamento completo. O inverso foi verificado nos tratamentos em que ocorreu a omissão de N, P, K e Mg, com maiores valores de CBF e menores CBS e CBH (Tabela 2). A correlação negativa entre $\mathrm{CBF}$ e $\mathrm{CBH}(\mathrm{r}=0,60)$, embora não significativa, indica que os tratamentos com maior concentração de carboidratos nas folhas acarretaram menor translocação de carboidratos para as hastes florais, o que pode prejudicar a durabilidade pós-colheita, como observado através da correlação de CBH e POSC $(r=0,57)$.

$\mathrm{O}$ teor de carboidratos das hastes florais $(\mathrm{CBH})$ no tratamento completo $\left(27,06 \mathrm{mg} \mathrm{L}^{-1}\right)$ diferiu dos teores observados nos tratamentos com omissão de N (5,27 mg L $\left.\mathrm{m}^{-1}\right), \mathrm{P}\left(3,92 \mathrm{mg} \mathrm{L}^{-1}\right), \mathrm{Mg}\left(17,57 \mathrm{mg} \mathrm{L}^{-1}\right) \mathrm{e}$ $\mathrm{Ca}\left(17,10 \mathrm{mg} \mathrm{L}^{-1}\right)$. Nowak \& Rudnicki (1990) afirmaram que hastes florais com maior conteúdo de carboidratos apresentam maior durabilidade, bem como maior intensidade de coloração das pétalas, fato observado nas hastes florais do tratamento completo.

Além disso, em plantas cultivadas com a solução completa, observou-se que o teor de carboidratos solúveis na haste floral $(\mathrm{CBH})$ foi o dobro do teor obtido na folha $(\mathrm{CBF})$, o que sugere grande exportação de carboidratos no processo de floração. Em Heliconia caribea, Yee \& Tissue (2005) também observaram menores concentrações de açúcares solúveis nas folhas do que nas estruturas florais. O teor de amido, no entanto, foi similar nas folhas e estruturas florais. No que se refere ao período da floração, o teor de amido praticamente não varia nas folhas, ao passo que o teor de carboidratos solúveis decresce, o que indica que a floração é mantida principalmente pela fotossíntese que ocorre durante esta fase fenológica. Segundo Druege (2000, 2001), as fases de floração e frutificação precisam de energia, sendo esperado que ocorra acúmulo de carboidratos em regiões (órgãos) de dreno como as inflorescências.

$\mathrm{O}$ teor de carboidratos nas folhas (CBF), no tratamento completo $\left(14,04 \mathrm{mg} \mathrm{L}^{-1}\right)$, foi inferior aos teores observados nos tratamentos com omissão de $\mathrm{N}$ (24,52 $\left.\mathrm{mg} \mathrm{L}^{-1}\right), \mathrm{P}\left(35,25 \mathrm{mg} \mathrm{L}^{-1}\right), \mathrm{K}\left(30,33 \mathrm{mg} \mathrm{L}^{-1}\right)$ e S $\left(24,32 \mathrm{mg} \mathrm{L}^{-1}\right)$. Estes resultados, associados à correlação positiva entre CBF e NDEI $(r=0,75)$, indicam que plantas com maiores teores de carboidratos solúveis na folha levaram mais tempo para iniciar o florescimento, como observado em todos os tratamentos com exceção do tratamento completo e com omissão de $\mathrm{Mg}$.

$\mathrm{O}$ teor de carboidrato na parte subterrânea (CBS), no tratamento completo $\left(32,30 \mathrm{mg} \mathrm{L}^{-1}\right)$, foi maior que os teores observados nos demais tratamentos, excetuando-se o tratamento com omissão de S. A correlação positiva entre CBS e MSH $(r=0,90)$ é indicação de que um acúmulo maior de carboidratos nas raízes e rizoma proporciona hastes florais com maior massa de matéria seca e, conseqüentemente, maior durabilidade pós-colheita.

No tratamento com omissão de P observou-se, concomitantemente ao menor teor de carboidratos na haste floral, o maior teor de carboidratos na folha (Tabela 2). Pieters et al. (2001) observaram que a omissão de $\mathrm{P}$ resultou em decréscimo na exportação de carbono das folhas (fonte), que foi quatro vezes inferior à exportação de carbono das folhas de plantas com suprimento adequado de $\mathrm{P}$. O acúmulo do produto final (carboidratos) foi um fator limitante da fotossíntese em plantas sob deficiência de P. Existem evidências de que as plantas usam os carboidratos como recurso energético para o período reprodutivo e que a alocação de carboidratos pode variar consideravelmente entre espécies (Yee \& Tissue, 2005).

A deficiência de $\mathrm{K}$ resultou em menores valores de massa de matéria seca da haste floral, durabilidade pós-colheita, paralelamente ao acúmulo de carboidratos nas folhas. Sob deficiência de K, as plantas acumulam 
mais carboidratos nas folhas e esse acúmulo está associado com a restrição do transporte da sacarose, redução da produção de matéria seca e alteração no padrão de partição de fotoassimilados entre os tecidos da planta (Zhao et al., 2001; Hermans et al., 2006).

Segundo Yee e Tissue (2005), na fase de florescimento, os teores de carboidratos variam muito entre as brácteas e outras partes da planta. $\mathrm{O}$ acúmulo de amido no pecíolo, rizoma e brácteas de $H$. caribeae, sugere que esse tipo de carboidrato não é utilizado para a produção da flor e sim acumulado para potencial uso na produção de frutos. Neste caso, como as hastes são utilizadas como flor de corte, quanto maior esse acúmulo, maior a durabilidade pós-colheita.

As inflorescências produzidas pelas plantas, no tratamento com omissão de $\mathrm{N}$, apresentaram brácteas com coloração mais pálida e deformações, quando comparadas com as inflorescências produzidas no tratamento completo (Figura 1). Chitarra \& Chitarra (2005) relatam que a deficiência de $\mathrm{N}$ prejudica a coloração de vários produtos hortícolas. $\mathrm{O}$ aspecto geral das inflorescências dos demais tratamentos foi semelhante ao das inflorescências do tratamento completo.

Todos os perfilhos produzidos por plantas de Heliconia, cultivar Golden Torch, apresentam potencial para emitir

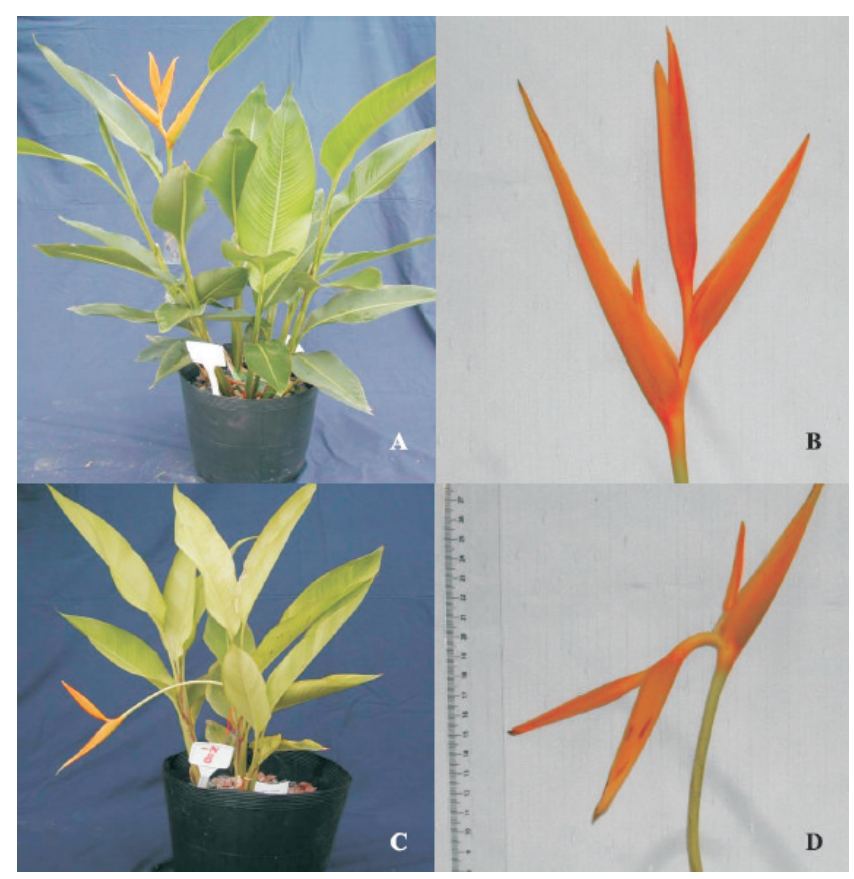

Figura 1. Heliconia psittacorum x H. spathocircinata, cultivar Golden Torch, cultivada em solução completa (A e B) e com omissão de nitrogênio (C e D). as inflorescências (Catley \& Brooking, 1986b). No entanto, notou-se que perfilhos emitidos de plantas submetidas à omissão de nutrientes podem não florescer. No tratamento completo, quatro perfilhos floresceram até 260 DAP (Figura 2). Nos tratamentos com omissão de nutrientes, foi observado que $100 \%$ dos primeiros perfilhos emitiram hastes florais. Os tratamentos com omissão de N, P, K e Mg reduziram a produção de hastes florais a partir do segundo perfilho, a omissão de $\mathrm{S}$ a partir do terceiro perfilho e a omissão de $\mathrm{Ca}$ a partir do quarto perfilho. A aplicação de doses crescentes de $\mathrm{N}$, $\mathrm{Pe} \mathrm{K}$ em condições de campo favoreceu a produtividade de Heliconia, cultivar Golden Torch (Ferreira \& Oliveira, 2003). Não foi observada formação de inflorescências nas plantas mantidas apenas com água destilada, o que indica que as reservas dos rizomas não foram suficientes para assegurar o florescimento dos perfilhos emitidos.

As omissões de N, P e $\mathrm{K}$ afetaram o $\mathrm{CH}, \mathrm{DH}, \mathrm{CI}$, POSC e teores de carboidratos solúveis totais, que são características importantes em uma haste floral, pois definem a quantidade e a qualidade para comercialização do produto final. Embora os resultados para a maioria das características avaliadas nos tratamentos com omissão de $\mathrm{Ca}$ e $\mathrm{Mg}$ tenham sido semelhantes aos observados no tratamento completo, as omissões desses nutrientes reduziram a durabilidade pós-colheita em até quatro dias $(25,64 \%)$.

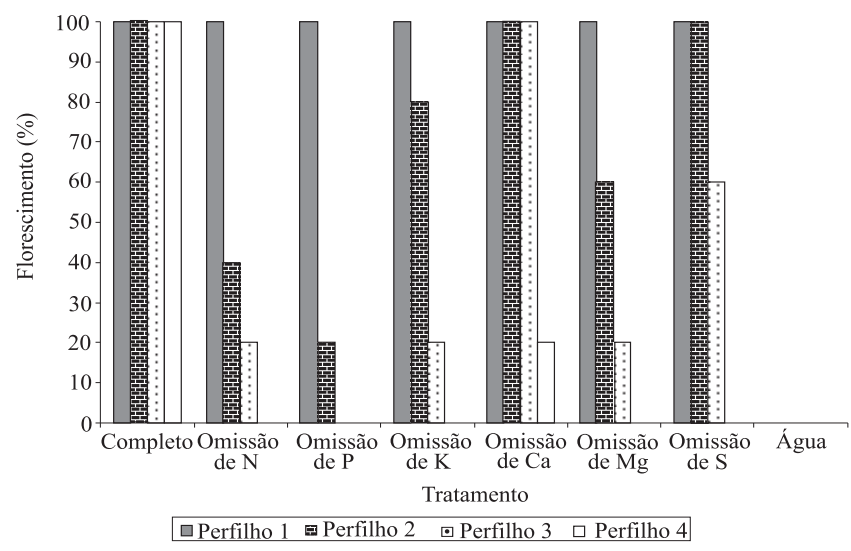

Figura 2. Porcentagem de florescimento dos quatro primeiros perfilhos emitidos de Heliconia psittacorum $\mathrm{x}$ H. spathocircinata, cultivar Golden Torch, cultivada em solução completa, com omissão de nitrogênio, fósforo, potássio, cálcio, magnésio ou enxofre e ausência de macronutrientes (água), aos 260 dias após o plantio. 
Ao se considerar que as plantas dos tratamentos com omissão dos macronutrientes apresentaram prejuízo nas características pós-colheita das hastes florais, é evidente que a qualidade delas pode ser melhorada por meio da adequada adubação, com destaque para o fornecimento de N, P e K.

\section{Conclusões}

1. Características importantes para pós-colheita e comercialização de Heliconia psittacorum x H. spathocircinata, cultivar Golden Torch, como comprimento e diâmetro da haste, comprimento da inflorescência, durabilidade pós-colheita e teor de carboidratos das hastes florais são comprometidas quando ocorre deficiência de nitrogênio, fósforo e potássio.

2. A omissão de macronutrientes afeta a produção de hastes florais a partir do segundo perfilho.

3. Hastes florais com maior massa de matéria seca e diâmetro apresentam maior durabilidade pós-colheita.

4. Maior acúmulo de carboidratos nas raízes e rizoma proporciona maior massa de matéria seca nas hastes florais.

5. Maiores teores de carboidratos solúveis nas folhas retardam a emissão da inflorescência.

\section{Agradecimentos}

À Capes, pela bolsa concedida; à UFRPE, Laboratórios de Floricultura e Química Agrícola; ao Banco do Nordeste - Etene/Fundeci, pelo financiamento do projeto.

\section{Referências}

BEZERRA NETO, E.; BARRETO, L.P. Métodos de análises químicas em plantas. Recife: UFRPE, 2004. 148p.

BROSCHAT, T.K. Production and postharvest culture of Heliconia psittacorum in South Florida. Bulletin Heliconia Society International, v.1, p.6, 1985.

CASTRO, C.E.F. Helicônias como flores de corte: adequação de espécies e tecnologia pós-colheita. 1993. 191p. Tese (Doutorado) - Universidade de São Paulo, Piracicaba.

CATLEY, J.; BROOKING, I. Shoot development and flowering of Heliconia 'Golden Torch'. Bulletin Heliconia Society International, v.8, p.1-4, 1996a.

CATLEY, J.; BROOKING, I. Temperature and light influence growth and flower production in Heliconia 'Golden Torch'. Hortscience, v.31, p.213-217, 1996b.
CECHIN, I.; FUMIS, T.F. Effect of nitrogen supply on growth and photosynthesis of sunflower plants grown in the greenhouse. Plant Science, v.166, p.1379-1385, 2004.

CHITARRA, M.I.F.; CHITARRA, A.B. Pós-colheita de frutas e hortaliças: fisiologia e manuseio. 2.ed. Lavras: UFLA, 2005. 785p.

CLEMENS, J.; MORTON, R.H. Optimizing mineral nutrition for flowers production in Heliconia 'Golden Torch' using response surface methodology. Journal of American Society of Horticultural Science, v.124, p.713-718, 1999.

COSTA, A.S. Características agronômicas e genéticas de helicônias na Zona da Mata de Pernambuco. 2005. 80p. Dissertação (Mestrado) - Universidade Federal Rural de Pernambuco, Recife.

DONSELMAN, H.M.; BROSCHAT, T.K. Production of Heliconia psittacorum for cut flowers in South Florida. Bulletin Heliconia Society International, v.1, p.4-6, 1986.

DRUEGE, U. Influence of pre-harvest nitrogen supply on postharvest behaviour of ornamentals: importance of carbohydrate status, photosynthesis and plant hormones. Gartenbauwissenschaft, v.65, p.52-64, 2000.

DRUEGE, U. Postharvest responses of different ornamental products to preharvest nitrogen supply: role of carbohydrates, photosynthesis and plants hormones. Acta Horticulturae, n.543, p.97-105, 2001.

FERNANDES, E.P. Crescimento e produção de Heliconia psittacorum em função de adubação mineral e densidade de plantio. 2000. 90p. Dissertação (Mestrado) - Universidade Federal de Goiás, Goiânia.

FERREIRA, L.B.; OLIVEIRA, S.A. Estudo de doses de NPK nas variáveis de crescimento e produtividade de inflorescências de Heliconia sp. Revista Brasileira de Horticultura Ornamental, v.9, p.121-127, 2003.

HERMANS, C.; HAMMOND, J.P.; WHITE, P.J.; VERBRUGGEN, N. How do plants respond to nutrient shortage by biomass allocation? Trends in Plant Science, v.11, p.610-617, 2006.

HOAGLAND, D.R.; ARNON, D.I. The water culture method for growing plants without soil. Berkeley: California Agricultural Experiment Station, 1951.34p. (Circular).

JUNQUEIRA, A.H.; PEETZ, M.S. Comercialização: aspectos de mercado e manuseio pós-colheita. In: TERAO, D.; CARVALHO, A.C.P.P.; BARROSO, T.C.S.F. (Ed.). Flores tropicais. Brasília: Embrapa Informação Tecnológica; Fortaleza: Embrapa Agroindústria Tropical, 2005. p.173-181.

JUNQUEIRA, A.H.; PEETZ, M.S. Las exportaciones brasileñas de flores y plantas ornamentales crecen más del $124 \%$ entre 2001 y 2006. Horticultura Internacional, n.56, p.76-78, 2007.

KAYS, S.J. Postharvest physiology of perishable plant products. New York: An Avi Book. 1991. 532p.

LAMAS, A.M. Floricultura tropical: técnicas de cultivo. Recife: Sebrae/PE, 2002. 88p.

LOGES, V.; TEIXEIRA, M.C.F.; CASTRO, A.C.R.; COSTA, A.S. Colheita, pós-colheita e embalagem de flores tropicais em Pernambuco. Horticultura Brasileira, v.23, p.699-672, 2005. 
MALAVOLTA, E. Manual de nutrição mineral de plantas. São Paulo: Agronômica Ceres, 2006. 638p.

MARISSEN, N. Effects of pre-harvest light intensity and temperature on carbohydrate levels and vase life of cut roses. Acta Horticulturae, n.543, p.331-343, 2001.

MARSCHNER, H. Mineral nutrition of higher plants. London: Academic Press, 1995. 889p.

MENGEL, K.; KIRKBY, E.A. Principles of plant nutrition. 5.ed. Dordrecht: Kluwer Academic Publishers, 2001. 864p.

NOWAK, J.; RUDNICKI, R.M. Postharvest handling and storage of cut flowers, florist greens and potted plants. Portland: Timber Press, 1990. 210p.

PIETERS, A.J.; PAUL, M.J.; LAWLOR, D.W. Low sink demand limits photosynthesis under Pi deficiency. Journal of Experimental Botany, v.52, p.1083-1091, 2001.

SALOMÃO, L.C.C.; SIQUEIRA, D.L.; PEREIRA, M.E.C. Acúmulo de macro e micronutrientes nas folhas e caules do ramo produtivo da lichieira 'Bengal' durante um ano. Ciência Agrotécnica, v.30, p.9-14, 2006.

VALLESPIR, A.N. Comércio ornamental: Brasil y el mercado mundial. Horticultura Internacional, n.47, p.12-26, 2005.

YEE, D.; TISSUE, D.T. Relationships between non structural carbohydrate concentration and flowering in a subtropical herb, Heliconia caribaea (Heliconiaceae). Caribbean Journal of Science, v.41, p.243-249, 2005.

YEH, M.D.; LIN, L.; WRIGHT, C.J. Effects of mineral nutrient deficiencies on leaf development, visual symptoms and shoot root ratio of Spathiphyllum. Scientia Horticulturae, v.86, p.223-233, 2000.

ZHAO, D.; OOSTERHUIS, D.M.; BEDNARZ, C.W. Influence of potassium deficiency on photosynthesis, chlorophyll content, and chloroplast ultrastructure of cotton plants. Photosynthetica, v.39, p.103-109, 2001.

Recebido em 2 de abril de 2007 e aprovado em 8 de agosto de 2007 